\title{
Heme oxygenase- 1 prevents non-alcoholic steatohepatitis through suppressing hepatocyte apoptosis in mice
}

\author{
YueMin Nan ${ }^{1 *}$, RongQi Wang ${ }^{1}$, SuXian Zhao ${ }^{1}$, Fang Han¹, Wen Juan Wu¹, LingBo Kong ${ }^{1}$, Na Fu', Li Kong ${ }^{1}$, Jun Yu²
}

\begin{abstract}
Objective: Heme oxygenase-1 (HO-1), the rate-limiting enzyme in heme catabolism, has been reported to have potential antioxidant properties. However, the role of $\mathrm{HO}-1$ on hepatocyte apoptosis remains unclear. We aim to elucidate the effects of $\mathrm{HO}-1$ on oxidative stress related hepatocellular apoptosis in nutritional steatohepatitis in mice.

Methods: C57BL/6J mice were fed with methionine-choline deficient (MCD) diet for four weeks to induce hepatic steatohepatitis. HO-1 chemical inducer (hemin), HO-1 chemical inhibitor zinc protoporphyrin IX (ZnPP-IX) and/or adenovirus carrying $\mathrm{HO}^{-1}$ gene (Ad-HO-1) were administered to mice, respectively. Hepatocyte apoptosis was evaluated by terminal deoxynucleotidyl transferase dUTP nick-end labeling (TUNEL) assay, the mRNA and protein expression of apoptosis related genes were assayed by quantitative real-time PCR and Western blot.

Results: Hepatocyte signs of oxidative related apoptotic injury were presented in mice fed with MCD diet for 4 weeks. Induction of $\mathrm{HO}-1$ by hemin or Ad-HO-1 significantly attenuated the severity of liver histology, which was associated with decreased hepatic lipid peroxidation content, reduced number of apoptotic cells by TUNEL staining, down-regulated expression of pro-apoptosis related genes including Fas/FasL, Bax, caspase-3 and caspase-9, reduced expression of cytochrome p4502E1 (CYP2E1), inhibited cytochrome c (Cyt-c) release, and up-regulated expression of anti-apoptosis gene $\mathrm{BCl}-2$. Whereas, inhibition of $\mathrm{HO}-1$ by ZnPP-IX caused oxidative stress related hepatic injury, which concomitant with increased number of TUNEL positive cells and up-regulated expression of pro-apoptosis related genes.
\end{abstract}

Conclusions: The present study provided evidences for the protective role of $\mathrm{HO}-1$ in preventing nutritional steatohepatitis through suppressing hepatocyte apoptosis in mice.

\section{Introduction}

Non-alcoholic steatohepatitis (NASH) is a chronic progressive liver disease which comprises steatosis, balloon degeneration, inflammation, and fibrosis in varying degrees [1]. The estimated prevalence of NASH is $3 \%-5 \%$ in general population [2]. Once NASH occurs, about 30\% $\sim 50 \%$ of individuals demonstrate advanced fibrosis or cirrhosis within a decade [3]. Up to now, the pathogenesis of NASH leading to disease progression remains poorly understood. The most widely accepted explanation is the two hit hypotheses [4], in which hepatocellular

\footnotetext{
* Correspondence: nanyuemin@163.com

'Department of Traditional and Western Medical Hepatology, Third Hospital of Hebei Medical University, Shijiazhuang, PR China

Full list of author information is available at the end of the article
}

apoptotic response associated with oxidative stress is considered to be the critical "hit" [5-8] in the transition from benign steatosis to steatohepatitis.

Heme oxygenase- 1 (HO-1) is a stress-responsive protein induced by various oxidative agents, and plays a fundamental role against the oxidative process [9]. It cleaves pro-oxidant heme into equimolar amounts of carbon monoxide (CO), biliverdin/bilirubin (BV/BR), and free iron [10]. These enzymatic reaction products have significant and useful biological properties, such as antioxidant, anti-inflammatory and anti-apoptotic activities [11-14]. A lack of HO-1 in either transgenic mice or in humans significantly increases apoptotic cell death $[15,16]$. Although a role of HO-1 as an antioxidant has been reported in many studies, the therapeutic potential 
of $\mathrm{HO}-1$ in steatohepatitis through mediating apoptosis is still unknown. In this study, we examine the effect of HO-1 on hepatocellular apoptosis in the pathogenesis of steatohepatitis in mice.

\section{Materials and methods}

\section{Animals and treatments}

Eight-week-old male C57BL/6J mice were bred and housed as previously described [17]. Mice were randomly divided into 7 groups (6 mice per group): 1) MCD group, mice fed methionine-choline deficient diet (ICN, Aurora, Ohio, USA); 2) control group, mice fed MCD diet supplemented with choline bitartate $(2 \mathrm{~g} / \mathrm{kg})$ and DL-methionine (3 g/ kg) (ICN, Aurora, Ohio); 3) $\mathrm{MCD}+$ hemin group, mice fed MCD diet administered with $\mathrm{HO}-1$ chemical inducer hemin $(30 \mu \mathrm{mol} / \mathrm{kg})$ by intraperitoneal (i.p.) injections three times per week; 4) $\mathrm{MCD}+\mathrm{ZnPP}$ group, mice fed MCD diet administered with HO-1 inhibitor ZnPP-IX (20 $\mathrm{mol} / \mathrm{kg})$ by i.p. injections three times per week; 5) MCD+Ad-GFP group, mice fed control diet administered with adenovirus encoding green fluorescent protein $\left(2.5 \times 10^{8}\right.$ Plaqueforming units (pfu) by i.p. injections two times per week; 6) MCD+Ad-HO-1 group, mice fed MCD diet administered with, adenovirus encoding the full-length mouse HO-1 $\left(2.5 \times 10^{8} \mathrm{pfu}\right)(\mathrm{Ad}-\mathrm{HO}-1)$ by i.p. injections two times per week; 7) MCD+hemin+Ad-HO-1 group, mice fed MCD diet administered with hemin and Ad-HO-1. At the end of the experiment for 4 weeks, all of the animals were sacrificed after overnight fasting. Livers were weighed and fixed in $10 \%$ formalin for histological analysis or snap-frozen in liquid nitrogen followed by storage at $-80^{\circ} \mathrm{C}$ freezer until required. All the protocols and procedures were carried out in accordance with the guidelines of the Hebei Committee for Care and Use of Laboratory Animals and were approved by the Animal Experimentation Ethics Committee of the Hebei Medical University.

\section{Construction of recombinant adenovirus}

A recombinant adenovirus containing the entire coding sequence of mouse HO-1 (Ad-HO-1) and control adenovirus encoding green fluorescent protein (Ad-GFP) were purchased from Tianjin Saier Biochemistry company limited (Tianjin, China). Adenovirus was propagated, isolated in human embryonic kidney 293 (HEK 293) cells and purified with Adeno-X Virus Purification kit (Clontech, Mountain View, CA, USA). Titer of the viral solution was determined by Adeno-X Rapid Titer kit (Clontech). The virus was stored at $-80^{\circ} \mathrm{C}$ until use. Mice were given intraperitoneal injection of Ad-HO-1 or Ad-GFP at an amount of $2.5 \times 10^{8}$ PFU suspended in $100 \mu \mathrm{l}$ phosphate-buffered saline two times per week.

\section{TUNEL assay}

$4 \mu \mathrm{m}$ liver sections were deparaffinized in xylene and hydrated in graded ethanol, and terminal deoxynucleotidyl transferase dUTP nick-end labeling (TUNEL) assay was performed following manufacturer's instructions and the apoptotic cells were identified using a Cell Death Detection kit (Roche Molecular Biochemicals, Mannheim, Germany). Ten random fields from 3 slides per group were examined, and the TUNEL-positive brown nuclei within the hepatocytes were counted as previously described [18]. The data were expressed as the number of TUNEL-positive cells/high- power field $(\times 400)$.

\section{Determination of thiobarbituric acid-reactant contents of the livers}

Liver lipoperoxide levels in tissue-homogenate supernatants were estimated using the thiobarbituric acidreactive substrances (TBARS) assay (Cell Biolabs, Inc. San Diego, CA) [19].

\section{Immunohistochemistry for HO-1}

Immunostaining for $\mathrm{HO}-1$ was performed in paraffinembedded liver sections using the specific antibody (Santa Cruz Biotechnology, Santa Cruz, CA) and an avidin-biotin complex (ABC) immunoperoxidase method. Briefly, endogenous peroxidase activity was blocked by treating sections with $3 \%$ hydrogen peroxide. The primary polyclonal rabbit antibody anti-HO-1 (dilution 1:100) was applied and incubated overnight at $4^{\circ} \mathrm{C}$. After extensive rinsing, the biotin-conjugated secondary antibody, ABC complex/horseradish peroxidase were applied for 30 minutes at room temperature. Peroxidase activity was visualized by applying diaminobenzidine to the sections, which were then counterstained with haematoxylin. Quantitative analysis of HO-1-stained liver sections was performed by morphometric analysis.

\section{Quantitation of hepatic messenger RNA expression levels}

Total RNA was extracted from the frozen liver tissues by using RNA Trizol reagent (Invitrogen, Carlsbad, CA). Five microgram of total RNA for each sample was reverse transcribed into complementary DNA (cDNA), the cDNA was diluted $1 / 100$ and $5 \mu$ l were used as a template per PCR reaction. The quantitative real-time PCR was performed on an ABI PRISM 7300 PCR System (Applied Biosystems, Foster City, CA) using Syber Green I GoTaq ${ }^{\circ}$ qPCR Master Mix (Promega BioSciences. Sunnyvale, CA). Expression levels of the target genes generated standard curves were normalized against an endogenous reference gene glyceraldehydes 3 -phosphate dehydrogenase (GAPDH). For each sample and each gene, PCR were carried out in duplicate and 
Table 1 Primers for real-time quantitative PCR analysis

\begin{tabular}{|c|c|c|}
\hline Gene & Product length & Primer sequences \\
\hline \multirow[t]{2}{*}{ CYP2E1 } & $199 \mathrm{bp}$ & F 5'-AACAGAGACCACCAGCACA-3' \\
\hline & & R 5'-GGAAGGGACGAGGTTGATGA-3' \\
\hline \multirow[t]{2}{*}{ Fas } & $504 \mathrm{bp}$ & F 5'-TGCGATTCTCCTGGCTGTGA-3' \\
\hline & & R 5'-GGTTCTGCGACATTCGGCTT-3' \\
\hline \multirow[t]{2}{*}{ FasL } & $345 \mathrm{bp}$ & F 5'-GAGTTCACCAACCAAAGCCTT-3' \\
\hline & & R 5'-CAACCTCTTCTCCTCCATTAGC-3' \\
\hline \multirow[t]{2}{*}{$\mathrm{BCl}-2$} & $100 \mathrm{bp}$ & F 5'-GGATGACTTCTCTCGTCGCTAC-3' \\
\hline & & R 5'-TGACATCTCCCTGTTGACGCT-3' \\
\hline \multirow[t]{2}{*}{ Bax } & $239 \mathrm{bp}$ & F 5'-GGTTGCCCTCTTCTACTTTGC-3' \\
\hline & & R 5'-TCTTCCAGATGGTGAGCGAG-3' \\
\hline \multirow[t]{2}{*}{ Cyt-C } & $157 \mathrm{bp}$ & F 5'-CGGCTGCTGTGATTGTGAAT-3' \\
\hline & & F 5'-TGTCTTGTGTTTCCCGCCTT-3' \\
\hline \multirow[t]{2}{*}{ caspase-3 } & $439 \mathrm{bp}$ & F 5'-ACGCAGCCAACCTCAGAGA-3' \\
\hline & & R 5'-ATGAACCACGACCCGTCCT-3' \\
\hline \multirow[t]{2}{*}{ caspase-9 } & $171 \mathrm{bp}$ & F 5'-TCCTCTCTTCATCTCCTGCTTAG-3' \\
\hline & & R 5'-ACTACTCTCTGCTCCTTTGCTG-3' \\
\hline \multirow[t]{2}{*}{ GAPDH } & $450 \mathrm{bp}$ & F 5'-ACCACAGTCCATGCCATCAC-3' \\
\hline & & R 5'-TCCACCACCCTGTTGCTG-3' \\
\hline
\end{tabular}

Abbreviations: CYP2E1, cytochrome p4502E1; Fas, death receptor; FasL, Fas Ligand; Cyt-C, cytochrome C; GAPDH, glyceraldehyde 3-phosphate dehydrogenase.

repeated twice. The specific primer sequences were listed in Table 1.

\section{Western blotting analysis of hepatic proteins}

Total protein was extracted and concentration was measured by the Bradford method (DC protein assay; BioRad, Hercules, CA). Equal amounts of protein $(100 \mathrm{mg} /$ well) were loaded onto $10 \%$ SDS-PAGE for each sample and proteins were transferred onto equilibrated polyvinylidene difluoride membranes (Amersham Biosciences, Buckinghamshire, UK) by electroblotting. Membranes were incubated overnight at $4^{\circ} \mathrm{C}$ with primary antibodies (Santa Cruz Biotechnology, Santa Cruz, CA). After incubation with the secondary antibody, proteins were detected by enhanced chemiluminescence (ECL, Amersham Corporation). The amount of protein expression was corrected by the amount of $\beta$-actin in the same sample and the bands were quantified by scanning densitometry using the digital Kodak Gel Logic 200 (Carestream Molecular Imaging, USA).

\section{Statistical analysis}

All data are expressed as mean \pm standard deviation (SD). Statistical analysis was carried out by one-way analysis of variance (ANOVA) and the Student-NewmanKeuls test for evaluating differences between groups using SPSS 13.0 (v.13.0; SPSS Inc., Chicago, III, USA). A $P$-value of less than 0.05 was considered statistically significant.

\section{Results}

Effect of HO-1 on hepatocyte apoptosis

As shown in Figure 1, TUNEL-positive cells appeared occasionally in the liver sections of control mice, but were frequently observed in mice fed with the MCD diet. TUNEL-positive cells were decreased by hemin or Ad-HO-1 administration. Treatment with hemin plus Ad-HO-1 did not further reduce the number of apoptotic cell. In contrast, TUNEL-positive cells were markedly increased by receiving $\mathrm{ZnPP}-\mathrm{IX}$ compared with the MCD diet alone.

\section{Effect of HO-1 induction on hepatic oxidative stress}

Hepatic level of oxidative stress was analyzed by TBARS assay (Figure 2). Mice fed with MCD diet resulted in a prominent increase in TBARS level compared with that of the control mice. A significant reduction of TBARS contents was noted after hemin treatment for 4 weeks compared to MCD-treated mice. A similar effect was observed by Ad-HO-1 gene transfer compared to mice administered Ad-GFP. The combination of hemin and Ad-HO-1 failed to show an additive effect on suppressing TBARS levels. However, the level of TBARS were markedly increased in mice treated with ZnPP-IX than those fed MCD diet only (Figure 2). Measurement of hepatic TBARS revealed that $\mathrm{HO}-1$ induction protected mice from oxidative injury.

\section{Induction of HO-1 by hemin and/or Ad-HO-1}

Immunohistochemical staining for $\mathrm{HO}-1$ was barely detectable in mice fed control diet (Figure 3), HO-1 staining was increased in liver sections of steatohepatitis mice fed the MCD diet, and appeared to be mainly in hepatocytes and kupffer cells both in the nuclei and cytoplasm, whereas in the sections of MCD-fed mice treated with hemin or Ad-HO-1, strong and dense $\mathrm{HO}-$ 1 immunoreactivity was observed, which paralleled the improvement in histological severity of steatohepatitis. Co-administration of hemin and Ad-HO-1 had no better effect on up-regulation of HO-1 expression. Conversely, in $\mathrm{ZnPP}-\mathrm{IX}$ treatment mice, hepatic protein expression of HO-1 was not observed in company with a pronounced liver injury (Figure 3 ).

\section{Effect of HO-1 on the expression of CYP2E1 and Cyt-C} The mRNA and protein expressions of lipid peroxidation mediator CYP2E1 were induced by MCD diet (Figure 4A1 and 4A2). The release of Cyt-c resulted from mitochondrial dysfunction also highly enhanced in MCD diet mice (Figure 4B1 and 4B2). Treatment with hemin or Ad-HO-1 prevented CYP2E1 induction and Cyt-c release. A similar effect was observed in hemin plus Ad-HO-1 group. Conversely, hepatic mRNA and 

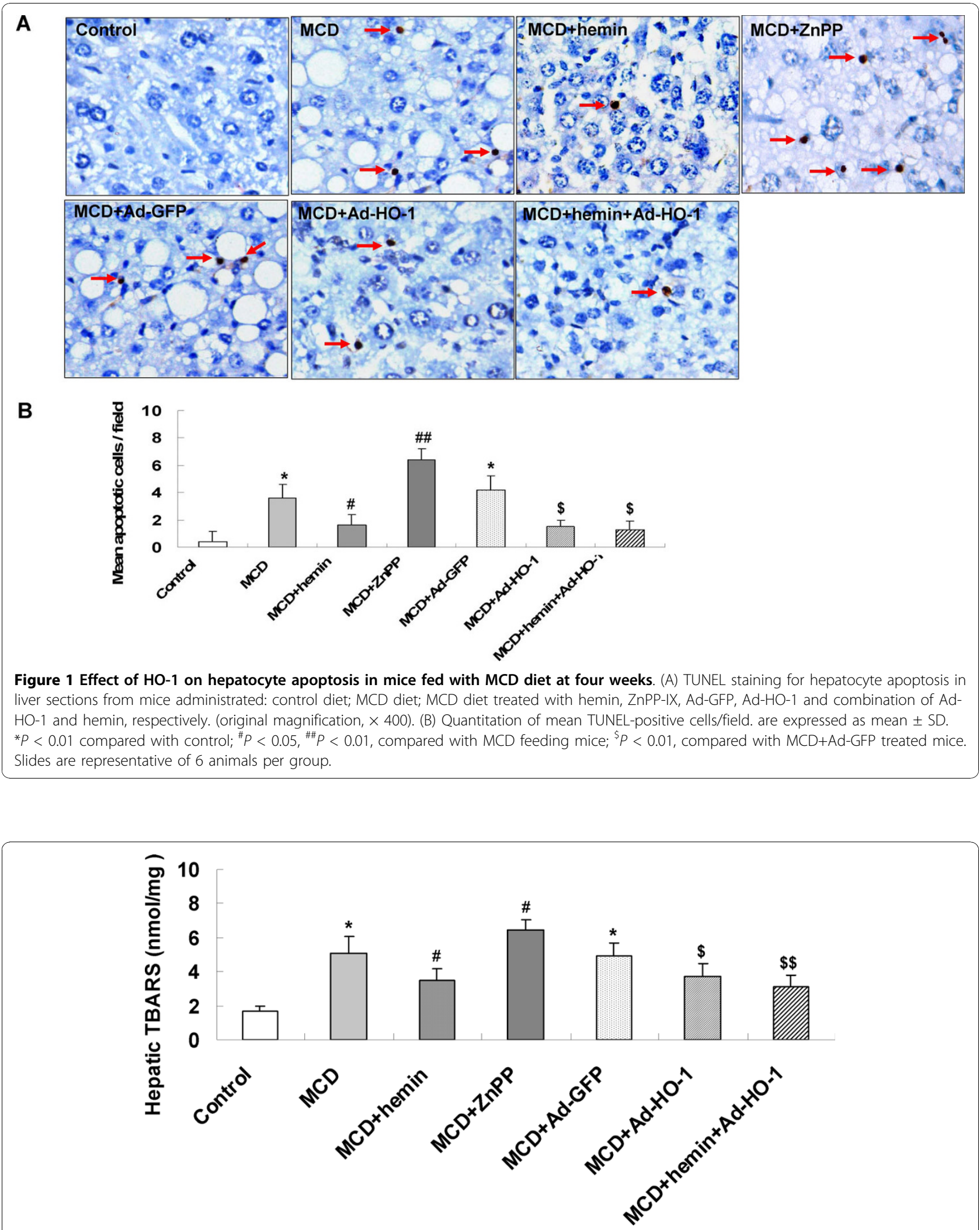

Figure 2 Effects of the MCD diet and treatment with hemin and/or Ad-HO-1 or ZnPP-IX on hepatic lipoperoxide content measured as thiobarbituric acid-reactive substrances (TBARS). Data are expressed as mean \pm SD ( $n=6$ per group). ${ }^{*} P<0.01$, ${ }^{* *} P<0.001$, compared with control; ${ }^{\#} P<0.05,{ }^{\# \#} P<0.01$, compared with MCD feeding mice; ${ }^{\$} P<0.05,{ }^{\$} P<0.01$, compared with MCD + Ad-GFP treated mice. 


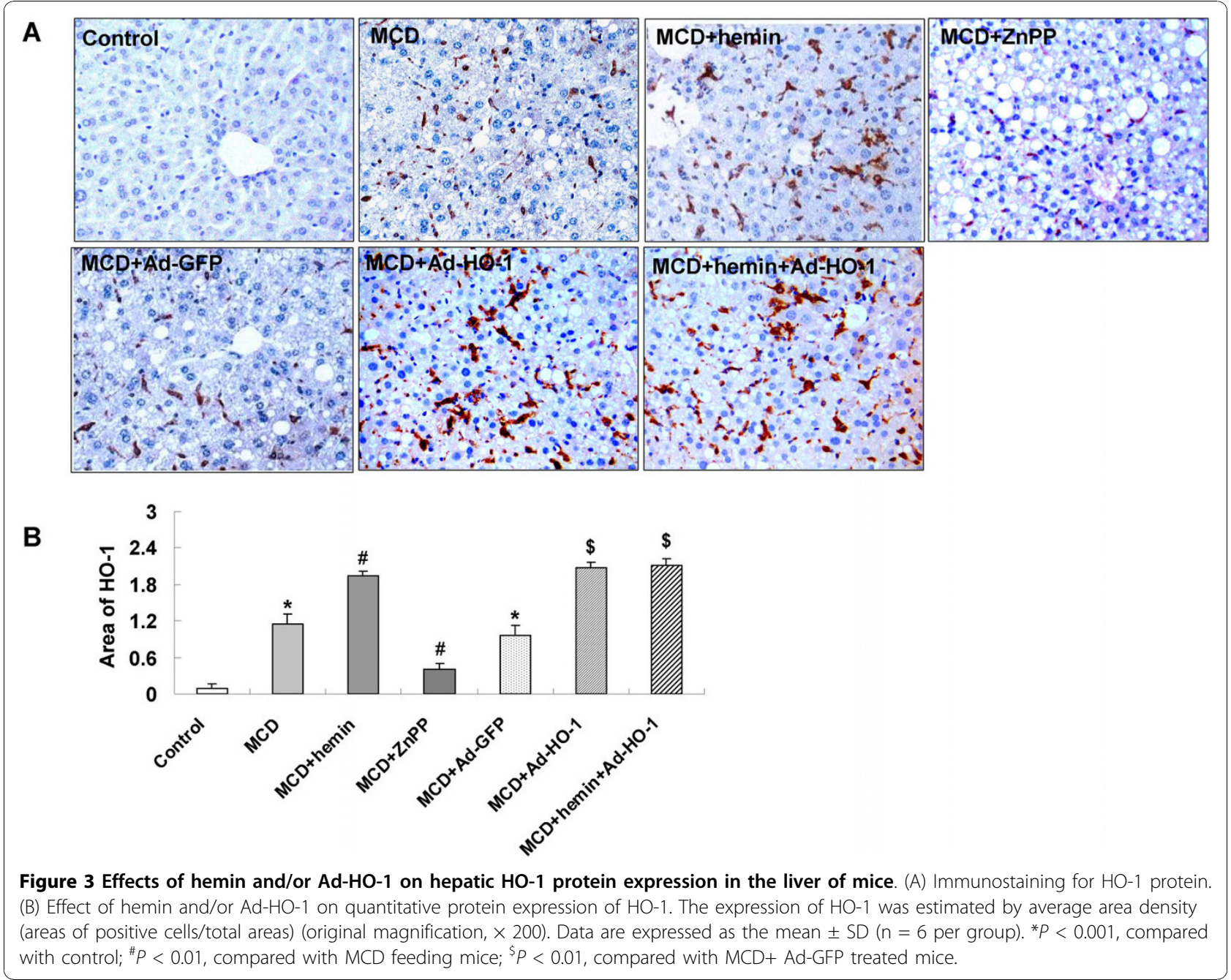

protein expression of CYP2E1 and Cyt-c was further upregulated by ZnPP-IX treatment as compared to MCD group.

\section{Effect of HO-1 induction on the expression of genes related to apoptosis}

To seek the role of HO-1 induction on cell apoptosis in the pathogenesis of steatohepatitis, we investigated expression levels of the key apoptosis-related genes. In MCD feeding mice, mRNA and protein expression of Fas (Figure 5A), FasL (Figure 5B), caspase-3 (Figure 6A), caspase-9 (Figure 6B), Bax (Figure 7A) had a marked elevation and the anti-apoptosis gene Bcl-2 (Figure 7B) was dramatically decreased. The expression of Fas/FasL, caspase-3, caspase-9 and Bax were down-regulated and $\mathrm{Bcl}-2$ was up-regulated by hemin or Ad-HO-1 administration. No further effect on regulating apoptosis genes expression was observed in administration of hemin and Ad-HO-1. In contrast, the expression of Fas/FasL, caspase-3, caspase-9 and Bax were further up-regulated and
Bcl-2 was further down-regulated by ZnPP-IX compared with mice fed a MCD diet.

\section{Discussion}

Following the MCD diet for 4 weeks, mice rapidly and consistently developed a steatohepatitis with steatosis, mixed inflammatory cell infiltration and hepatocellular necrosis which is in line with our previous report [20] and histologic similarities to human disease [21]. Accompany with the histological changes, there was a marked induction of hepatocyte apoptosis compared with the control mice. Treatment with $\mathrm{HO}-1$ selective inducer hemin or Ad-HO-1 significantly attenuated the MCDinduced hepatic apoptotic injury by induction of hepatic HO-1 protein levels, which was evidenced by reduction of hepatocyte apoptosis and amelioration of liver histology. However, the combination of Ad-HO-1 and hemin did not show a synergetic effect. In contrast, a pronounced liver injury and lowered $\mathrm{HO}-1$ immunostaining was presented by giving ZnPP-IX, a specific competitive 

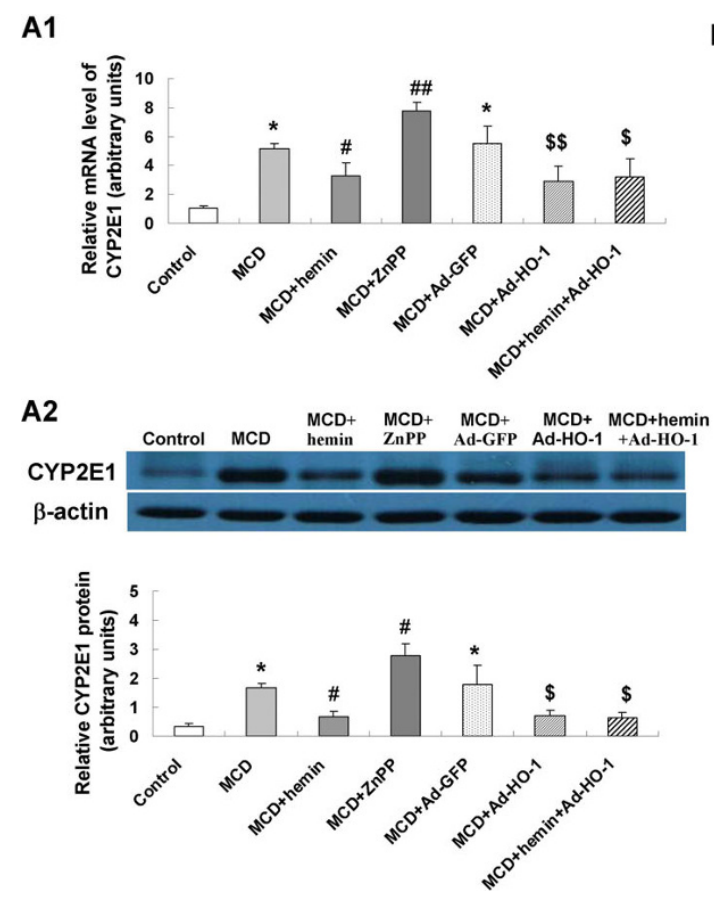

B1

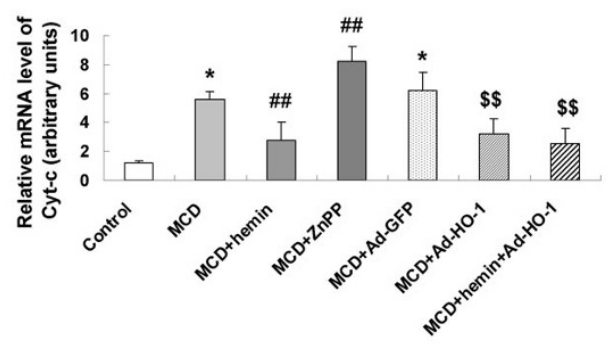

B2

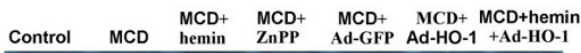

Cyt-C $\beta$-actin

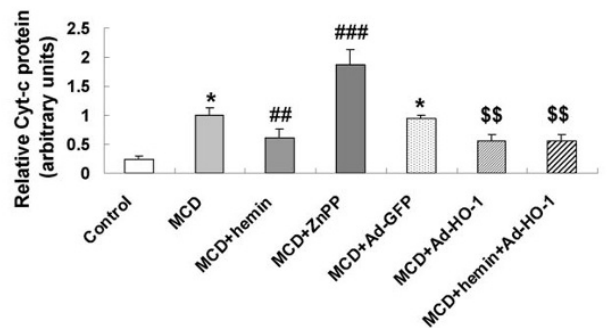

Figure 4 Effects of HO-1 on hepatic expression of cytochrome p450 2E1 (CYP2E1) (A) and cytochrome c (Cyt-c) (B). mRNA expression of CYP2E1 (A1) and Cyt-c mRNA(B1) was examined by real-time quantitative PCR; and protein expression of CYP2E1 (A2) and Cyt-C (B2) were measured by Western blot. Data are expressed as the mean \pm SD $\left(n=6\right.$ per group). ${ }^{*} P<0.001$, compared with control mice; ${ }^{\#} P<0.05$, ${ }^{\# \#} P<0.01$, $\# \# P<0.001$, compared with MCD mice; ${ }^{\$} P<0.05,{ }^{\$ \$} P<0.01$, compared with MCD+ Ad-GFP treated mice.
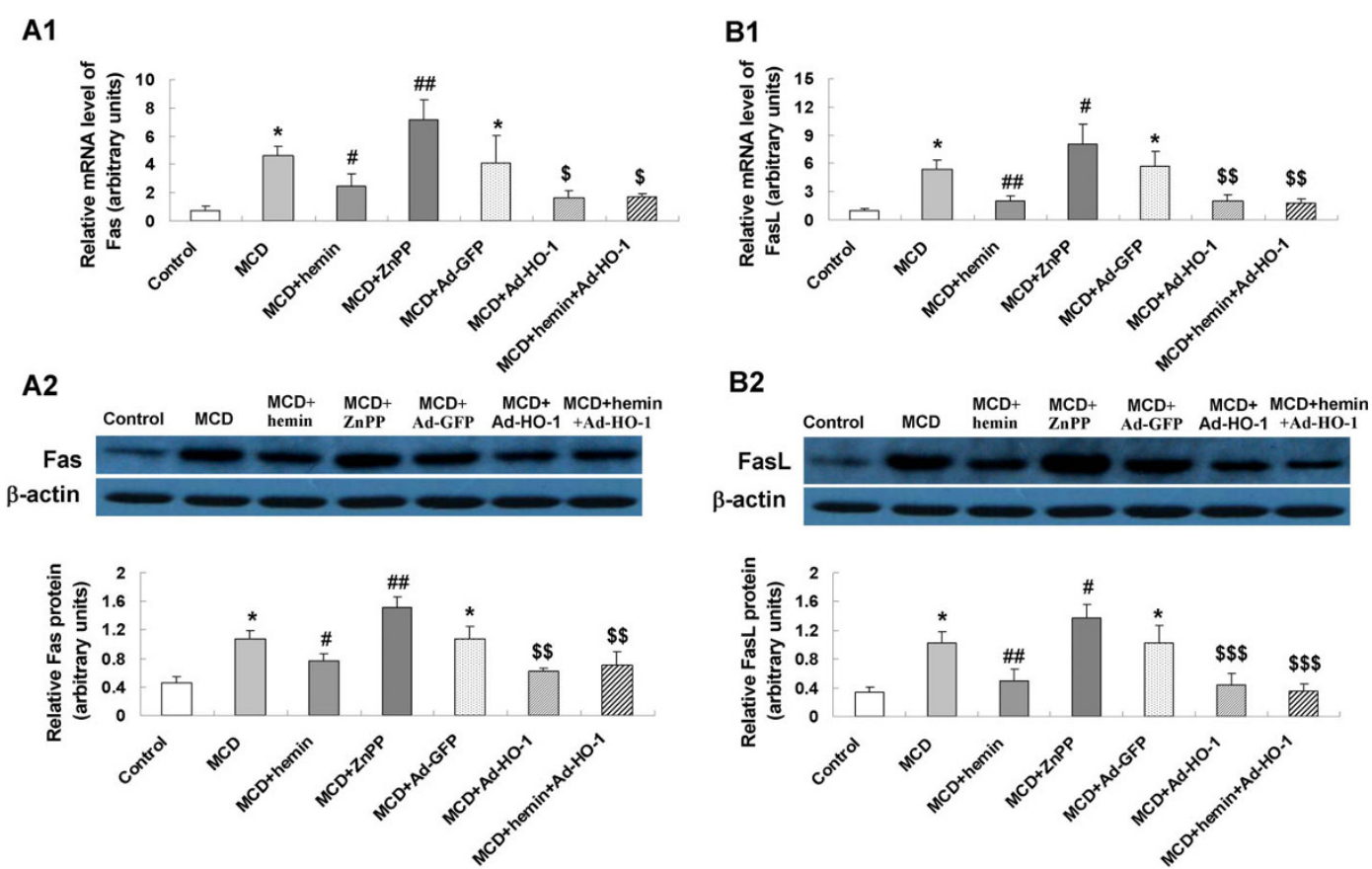

Figure 5 Effects of HO-1 on expression of FAS and FASL in the liver of mice. mRNA expression of Fas (A1) and Fasligand (FasL) (B1) was examined by real-time PCR; protein expression of Fas (A2) and FasL (B2) were measured by Western blot. Data are expressed as the mean \pm SD ( $n=6$ per group). ${ }^{*} P<0.001$, compared with control mice; ${ }^{\#} P<0.05,{ }^{\# \#} P<0.01$, compared with MCD mice; ${ }^{\$} P<0.05$, ${ }^{\$ \$} P<0.01,{ }^{\$ \$ \$} P<0.01$, compared with MCD+ Ad-GFP treated mice. 


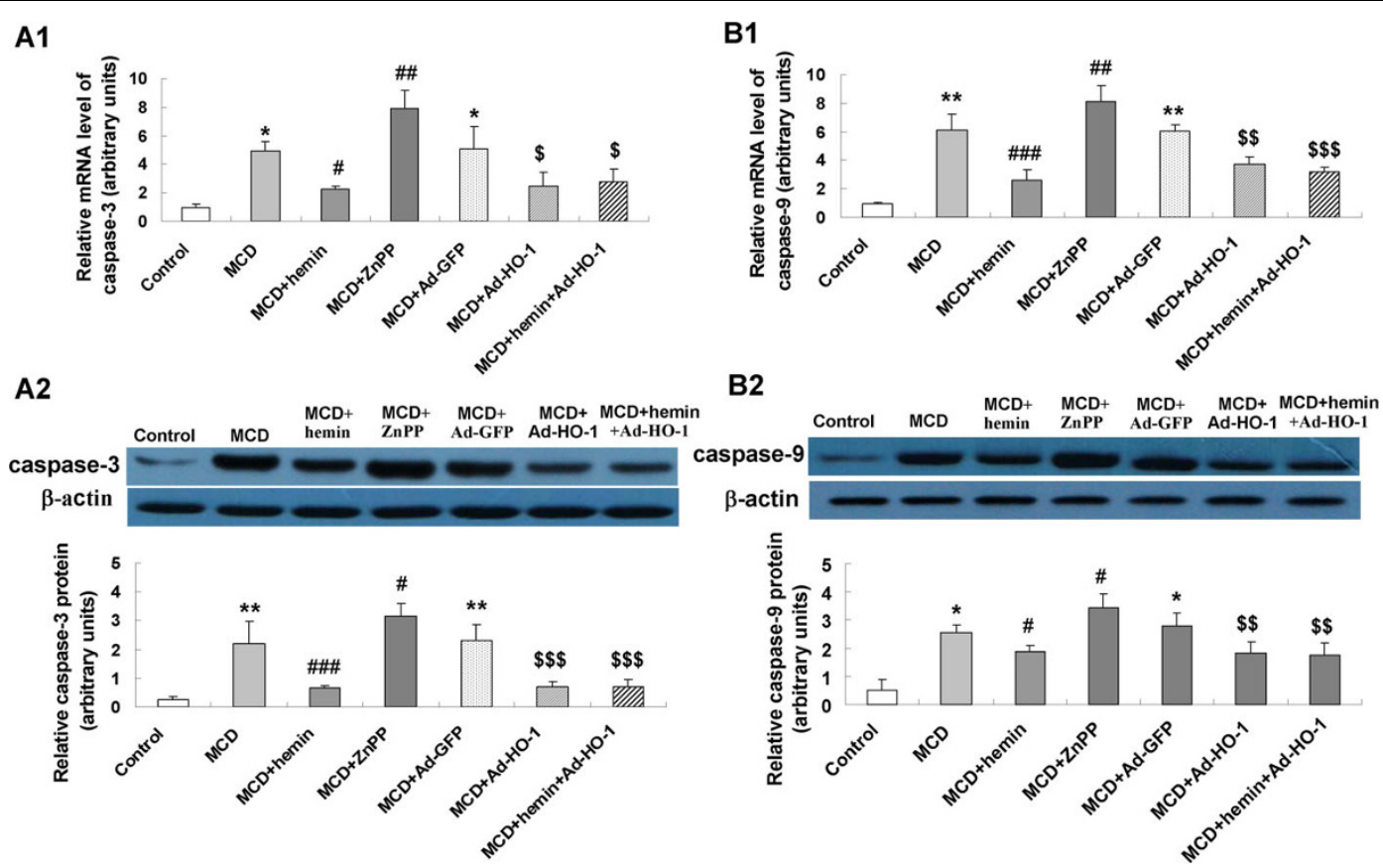

Figure 6 Effects of HO-1 on expression of caspase 3 and casepase 9 in the liver of mice. mRNA expression of casepase 3 (A1) and casepase 9 (B1) was examined by real-time PCR; protein expression of casepase 3 (A2) and casepase 9 (B2) were measured by Western blot.

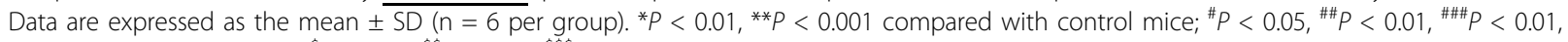
compared with MCD mice; ${ }^{\$} P<0.05,{ }^{\$ \$} P<0.01,{ }^{\$ \$ \$} P<0.01$, compared with MCD+ Ad-GFP treated mice.

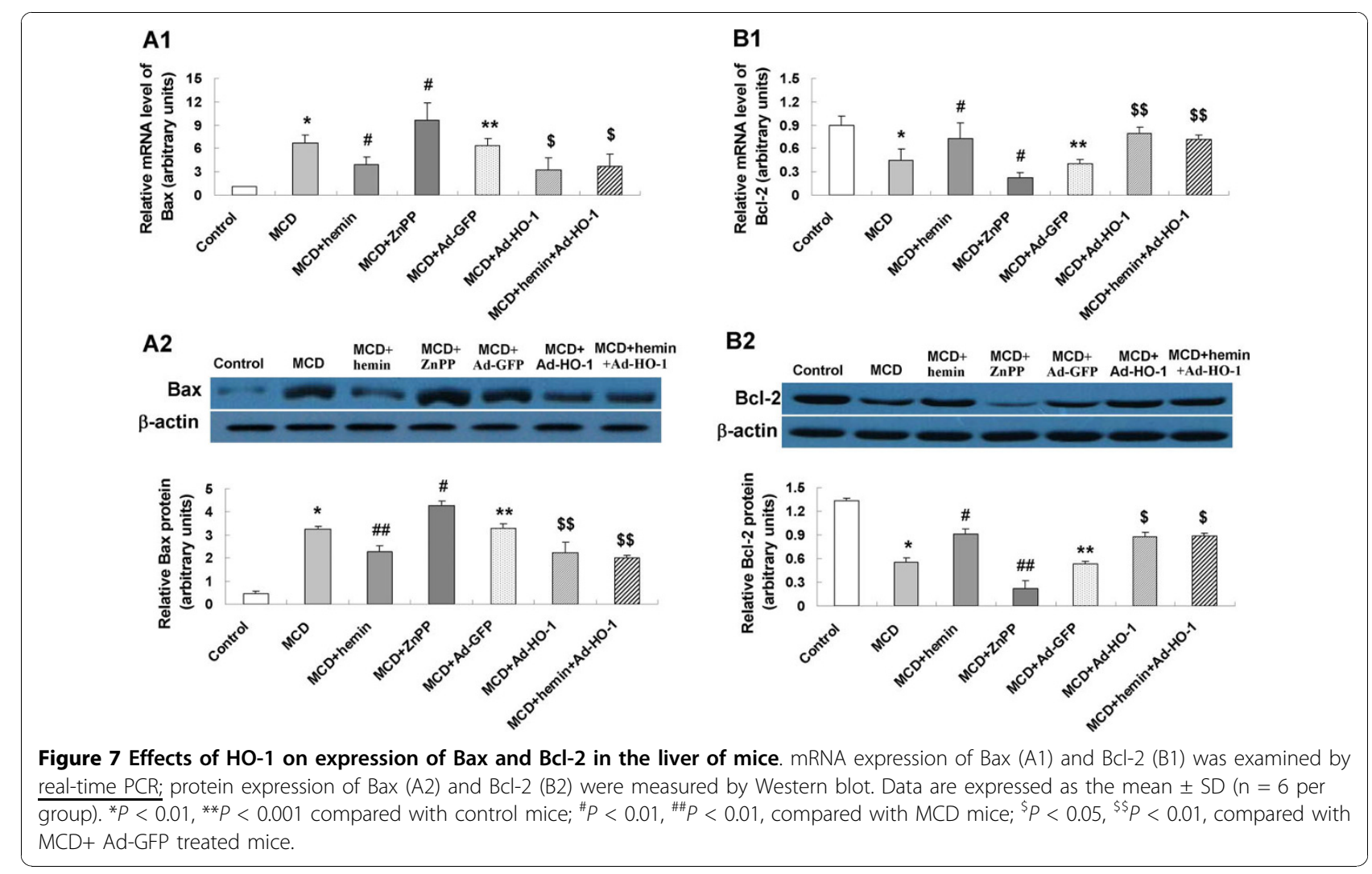


inhibitor of HO-1 [22]. It was reported that human liver generated comparable amounts of the HO-derived products in both kupffer cells and hepatocytes, and HO-1 induction protected against ischemia/reperfusion injury, oxidative stress, inflammation, apoptosis, transplant rejection, and other conditions [12]. Our data show that HO-1 is up-regulated by hemin or Ad-HO-1, which might play an important role in protection against hepatic apoptotic injury caused by MCD diet.

In fatty liver, surplus of fatty acids and excessive oxidation lead to production of reactive oxygen species (ROS) and oxidative stress, which will trigger inflammatory response and apoptosis [23]. Excessive production of ROS generated from microsomal, mitochondrial, and other pro-oxidant pathways may eventually overwhelm antioxidant defenses and generate highly toxic lipid peroxides. The increased release of lipid peroxidation products bind to mitochondrial proteins, promote cytochrome $\mathrm{c}$ release [24], and then contribute to cell death. CYP2E1, a microsomal fatty acid oxidizing enzyme, is known to be a significant source of ROS [25]. Ethanol and dietary, as well as endogenously produced fatty acids, are inducers of and substrates for CYP2E1 [26]. It generates high amounts of hydrogen peroxide in the presence of oxidizable cosubstrates [27]. Enhanced CYP2E1 induction could oxidize mitochondrial DNA, proteins and lipids, and trigger hepatic tumor necrosis factor-alpha (TNF- $\alpha$ ) formation by activating nuclear factor-kappaB (NF- $\kappa \mathrm{B})$, thus further increase mitochondrial ROS formation, and then lead to the inflammatory recruitment and apoptosis from oxidative stress [23]. In the present study, we found enhanced oxidative stress in the MCD-diet mice. Lipid peroxidation, as reflected by hepatic TBARS concentration and the mRNA and protein expression of CYP2E1 were significantly increased in mice fed a MCD diet compared with control mice. Treatment with hemin or Ad-HO-1 reduced hepatic TBARS levels and CYP2E1 expression. Consistent with our findings, Zhu et al. [28] have demonstrated that HO-1 up-regulation increased resistance to oxidantmediated cytotoxicity and reduced basal prooxidant levels. These results suggest that up-regulation of HO-1 expression attenuate oxidative stress and inhibit progression of liver injury, which probably is due to alleviated lipid peroxidation and CYP2E1 reduction.

It is now recognized that increased hepatocyte apoptosis is a prominent feature in steatohepatitis and correlates strongly with clinical and histologic disease severity $[29,30]$. The association between increased oxidative stress and a high rate of cellular apoptosis has been reported in hepatocytes [31]. To elucidate the mechanisms by which apoptosis occurs in the liver may provide an insight into the pathogenesis of steatohepatitis and identify possible treatments. We demonstrated that oxidative stress related hepatocyte apoptosis was enhanced by feeding mice MCD diet. Treatment with hemin or Ad-HO-1 resulted in significantly resistance to apoptosis, evidenced by diminution of the TUNEL-positive cells and down-regulated mRNA and protein expressions of key pro-apoptotic factors Fas/FasL, caspase-3, caspase-9, Bax and Cyt-c, and markedly increased anti-apoptotic $\mathrm{Bcl}-2$. Overproduction of ROS might induce apoptosis by inducing FasL to interact with Fas and formed a deathinducing signal complex (DISC) [32], activated caspase cascade including caspase- 8 and caspase- 3 to recruit hepatocytes to apoptosis [33]. Also ROS might promote onset of the mitochondrial permeability transition (MPT) by inducing translocation of Bax from cytosol to mitochondria and lead Cyt-c to release [34] to cause the cell apoptosis by formation of a complex with apoptotic protease-activating factor- 1 and activation of caspase- 9 and its downstream effectors caspases-3, 6 and $7[35,36]$. Thus, a common feature of the death receptor- and mitochondrion-dependent apoptosis is the activation of caspase-3 [37]. It was suggested that HO-1 mediated protection was accompanied by significantly reduced caspase- 3 activation [38]. HO-1 regulated mitochondrial transport carriers and function by activating Bcl-2 and $\mathrm{Bcl}-\mathrm{xL}$, preventing Cyt-c release and activation of caspases [39]. Increased HO-1 expression increased Bad, inhibited Cyt-c release and increased cell survival [40,41]. Collectively, the protective effect of $\mathrm{HO}-1$ on oxidative damage-induced apoptosis may be mediated via both the extrinsic pathway and the intrinsic apoptosis signaling pathways. HO-1 provides both antioxidant and antiapoptotic properties maybe due to its products of BV/BR, iron and $\mathrm{CO}$. BV/BR has been shown to defense against reactive oxygen species [38] and BV adjuvant therapy has been shown to protect rat liver grafts from ischemia/ reperfusion injury through suppressing Cyt-c release [42]. Iron induces ferritin, which in turn prevents lipid peroxidation [43]. CO has been exhibited anti-inflammatory and anti-apoptotic properties, which are thought to be mediated by activation of $\mathrm{p} 38$ mitogen-activated protein kinase (p38 MAPK) signaling pathway [44-46]. It has also been reported that the anti-apoptotic effect of $\mathrm{CO}$ involves in inhibition of Fas/FasL expression, and other apoptosis-related factors including caspases (especially caspase-3), mitochondrial Cyt-c release, and poly adpribose polymerase cleavage [47]. Clearly, further studies are still necessary to clarify both how and at which level HO-1 affects the two apoptosis signaling pathways.

In summary, the present study suggest that induction of HO-1 by pretreatment with hemin or Ad-HO-1 attenuated hepatic apoptosis injury in MCD diet-fed mice, which maybe regarded to alleviation of lipid peroxidation, suppression of CYP2E1 expression, down-regulation of Fas/FasL, caspase- 9 and caspase- 3 expression, reduction of Cyt-c release and modification of $\mathrm{Bcl}-2 / \mathrm{Bax}$ ratio. The 
present study provided evidences for the protective role of HO-1 in preventing nutritional steatohepatitis through suppressing hepatocyte apoptosis in mice.

\section{List of Abbreviations}

HO-1: heme oxygenase-1; MCD: methionine-choline deficient; NASH: nonalcoholic steatohepatitis; ZNPP-IX: zinc protoporphyrin IX; TUNEL: terminal deoxynucleotidyl transferase dUTP nick-end labeling; ROS: reactive oxygen species; CYT-C: cytochrome c; CYP2E1: cytochrome p4502E1; TBARS: thiobarbituric acid reactive substances.

\section{Acknowledgements}

This work was funded by the Hebei Natural Science Fund, No. C2009001183.

\section{Author details}

${ }^{1}$ Department of Traditional and Western Medical Hepatology, Third Hospital of Hebei Medical University, Shijiazhuang, PR China. ${ }^{2}$ Institute of Digestive Disease and Department of Medicine and Therapeutics, The Chinese University of Hong Kong, Hong Kong.

\section{Authors' contributions}

YN and JY designed the research; RW, SZ, FH, WW, LK and NF performed the research; YN and RW analyzed data; YN, RW and JY wrote the paper. All authors read and approved the final manuscript.

\section{Competing interests}

The authors report no conflicts of interest. The authors alone are responsible for the content and writing of the paper.

Received: 3 October 2010 Accepted: 28 October 2010 Published: 28 October 2010

\section{References}

1. Canbay A, Gieseler RK, Gores GJ, Gerken G: The relationship between apoptosis and non-alcoholic fatty liver disease: an evolutionary cornerstone turned pathogenic. Z Gastroenterol 2005, 43:211-217.

2. Jarrar MH, Baranova A, Collantes R, Ranard B, Stepanova M, Bennett C, Fang Y, Elariny H, Goodman Z, Chandhoke V, Younossi ZM: Adipokines and cytokines in non-alcoholic fatty liver disease. Aliment Pharmacol Ther 2008, 27:412-421.

3. Jou J, Choi SS, Diehl AM: Mechanisms of disease progression in nonalcoholic fatty liver disease. Semin Liver Dis 2008, 28:370-379.

4. Edmison J, McCullough AJ: Pathogenesis of non-alcoholic steatohepatitis: human data. Clin Liver Dis 2007, 11:75-104.

5. Mantena SK, King AL, Andringa KK, Eccleston HB, Bailey SM: Mitochondria dysfunction and oxidative stress in the pathogenesis of alcohol- and obesity-induced fatty liver diseases. Free Radic Biol Med 2008, 44:1259-1272.

6. Wang Y, Ausman LM, Russell RM, Greenberg AS, Wang XD: Increased apoptosis in high-fat diet-induced nonalcoholic steatohepatitis in rats is associated with c-Jun NH2-terminal kinase activation and elevated proapoptotic Bax. J Nutr 2008, 138:1866-1871

7. Syn WK, Choi SS, Diehl AM, Diehl AM: Apoptosis and Cytokines in NonAlcoholic Steatohepatitis. Clin Liver Dis 2009, 13:565-580.

8. Czaja MJ: Induction and regulation of hepatocyte apoptosis by oxidative stress. Antioxid Redox Signal 2002, 4:759-767.

9. Kawakami T, Takahashi T, Shimizu H, Nakahira K, Takeuchi M, Katayama H, Yokoyama M, Morita K, Akagi R, Sassa S: Highly liver-specific heme oxygenase- 1 induction by interleukin-11 prevents carbon tetrachlorideinduced hepatotoxicity. Int J Mol Med 2006, 18:537-546.

10. Tsui TY, Lau CK, Ma J, Wu X, Wang YQ, Farkas S, Xu R, Schlitt HJ, Fan ST: rAAV-mediated stable expression of heme oxygenase- 1 in stellate cells: a new approach to attenuate liver fibrosis in rats. Hepatology 2005, 42:335-342.

11. Takahashi T, Shimizu H, Morimatsu H, Inoue K, Akagi R, Morita K, Sassa S: Heme oxygenase-1: a fundamental guardian against oxidative tissue injuries in acute inflammation. Mini Rev Med Chem 2007, 7:745-753.

12. Ryter SW, Alam J, Choi AM: Heme oxygenase-1/carbon monoxide: from basic science to therapeutic applications. Physiol Rev 2006, 86:583-650.
13. Ryter SW, Kim HP, Nakahira K, Zuckerbraun BS, Morse D, Choi AM: Protective functions of heme oxygenase- 1 and carbon monoxide in the respiratory system. Antioxid Redox Signal 2007, 9:2157-2173.

14. Ryter SW, Morse D, Choi AM: Carbon monoxide and bilirubin: potential therapies for pulmonary/vascular injury and disease. Am J Respir Cell Mol Biol 2007, 36:175-182.

15. Quan S, Yang L, Abraham NG, Kappas A: Regulation of human heme oxygenase in endothelial cells by using sense and antisense retroviral constructs. Proc Natl Acad Sci USA 2001, 98:12203-12208,

16. Quan S, Kaminski PM, Yang L, Morita T, Inaba M, Ikehara S, Goodman Al, Wolin MS, Abraham NG: Heme oxygenase-1 prevents superoxide anionassociated endothelial cell sloughing in diabetic rats. Biochem Biophys Res Commun 2004, 315:509-516.

17. Nan YM, Fu N, Wu WJ, Liang BL, Wang RQ, Zhao SX, Zhao JM, Yu J: Rosiglitazone prevents nutritional fibrosis and steatohepatitis in mice. Scand J Gastroenterol 2009, 44:358-365.

18. Feldstein AE, Canbay A, Angulo P, Taniai M, Burgart $L J$, Lindor KD, Gores GJ: Hepatocyte apoptosis and fas expression are prominent features of human nonalcoholic steatohepatitis. Gastroenterology 2003, 125:437-443.

19. Puntel RL, Roos DH, Paixão MW, Braga AL, Zeni G, Nogueira CW, Rocha JB: Oxalate modulates thiobarbituric acid reactive species (TBARS) production in supernatants of homogenates from rat brain, liver and kidney: effect of diphenyl diselenide and diphenyl ditelluride. Chem Biol Interact 2007, 165:87-98.

20. Nan YM, Wu WJ, Fu N, Liang BL, Wang RQ, Li LX, Zhao SX, Zhao JM, Yu J: Antioxidants vitamin $E$ and 1-aminobenzotriazole prevent experimental non-alcoholic steatohepatitis in mice. Scand J Gastroenterol 2009, 44:1121-1131.

21. Farrell GC, Larter CZ, Hou JY, Zhang RH, Yeh MM, Williams J, dela Pena A Francisco R, Osvath SR, Brooling J, Teoh N, Sedger LM: Apoptosis in experimental NASH is associated with p53 activation and TRAIL receptor expression. J Gastroenterol Hepatol 2009, 24:443-452.

22. Nowis D, Bugajski M, Winiarska M, Bil J, Szokalska A, Salwa P, Issat T, Was $H$, Jozkowicz A, Dulak J, Stoklosa T, Golab J: Zinc protoporphyrin IX, a heme oxygenase-1 inhibitor, demonstrates potent antitumor effects but is unable to potentiate antitumor effects of chemotherapeutics in mice. BMC Cancer 2008, 8:197.

23. Schreuder TC, Verwer BJ, van Nieuwkerk CM, Mulder CJ: Nonalcoholic fatty liver disease: an overview of current insights in pathogenesis, diagnosis and treatment. World J Gastroenterol 2008, 14:2474-2486.

24. Landar A, Shiva S, Levonen AL, Oh JY, Zaragoza C, Johnson MS, DarleyUsmar VM: Induction of the permeability transition and cytochrome $c$ release by 15-deoxy-Delta12, 14-prostaglandin $\mathrm{J} 2$ in mitochondria. Biochem J 2006, 394(Pt1):185-195.

25. Koop DR: Alcohol metabolism's damaging effects on the cell: a focus on reactive oxygen generation by the enzyme cytochrome P450 $2 \mathrm{E} 1$. Alcohol Res Health 2006, 29:274-280.

26. Raucy JL, Lasker J, Ozaki K, Zoleta V: Regulation of CYP2E1 by ethanol and palmitic acid and CYP4A11 by clofibrate in primary cultures of human hepatocytes. Toxicol Sci 2004, 79:233-241.

27. Mantena SK, King AL, Andringa KK, Eccleston HB, Bailey SM: Mitochondrial dysfunction and oxidative stress in the pathogenesis of alcohol- and obesity-induced fatty liver diseases. Free Radic Biol Med 2008, 44:1259-1272.

28. Zhu Z, Wilson AT, Mathahs MM, Wen F, Brown KE, Luxon BA, Schmidt WN: Heme oxygenase- 1 suppresses hepatitis $C$ virus replication and increases resistance of hepatocytes to oxidant injury. Hepatology 2008, 48:1430-1439.

29. Canbay A, Gieseler RK, Gores GJ, Gerken G: The relationship between apoptosis and non-alcoholic fatty liver disease: an evolutionary cornerstone turned pathogenic. Z Gastroenterol 2005, 43:211-217.

30. Ribeiro PS, Cortez Pinto H, Sola S, Castro RE, Ramalho RM, Baptista A, Moura MC, Camilo ME, Rodrigues CM: Hepatocyte apoptosis, expression of death receptors, and activation of NF-kappaB in the liver of nonalcoholic and alcoholic steatohepatitis patients. Am J Gastroenterol 2004, 99:1708-1717.

31. Singh R, Czaja MJ: Regulation of hepatocyte apoptosis by oxidative stress. I Gastroenterol Hepatol 2007, 22(S1):S45-S48.

32. Walsh CM, Luhrs KA, Arechiga AF: The "fuzzy logic" of the death-inducing signaling complex in lymphocytes. J Clin Immunol 2003, 23:333-353. 
33. Morse D, Lin L, Choi AM, Ryter SW: Heme oxygenase-1, a critical arbitrator of cell death pathways in lung injury and disease. Free Radic Biol Med 2009, 47:1-12.

34. Riedl SJ, Salvesen GS: The apoptosome: signaling platform of cell death. Nat Rev Mol Cell Biol 2007, 8:405-413.

35. Lauber K, Bohn E, Krober SM, Xiao YJ, Blumenthal SG, Lindemann RK, Marini P, Wiedig C, Zobywalski A, Baksh S, Xu Y, Autenrieth IB, SchulzeOsthoff K, Belka C, Stuhler G, Wesselborg S: Apoptotic cells induce migration of phagocytes via caspase-3-mediated release of a lipid attraction signal. Cell 2003, 113:717-730.

36. Riedl SJ, Shi Y: Molecular mechanisms of caspase regulation during apoptosis. Nat Rev Mol Cell Biol 2004, 5:897-907.

37. Chen $\mathrm{M}$, Wang J: Initiator caspases in apoptosis signaling pathways. Apoptosis 2002, 7:313-319.

38. Sass G, Soares MC, Yamashita K: Heme oxygenase-1 and its reaction product, carbon monoxide, prevent inflammation-related apoptotic liver damage in mice. Hepatology 2003, 38:909-918.

39. Di Noia MA, Van Driesche S, Palmieri F, Yang LM, Quan S, Goodman Al, Abraham NG: Heme oxygenase-1 enhances renal mitochondrial transport carriers and cytochrome c oxidase activity in experimental diabetes. J Biol Chem 2006, 281:15687-15693.

40. Olszanecki R, Rezzani R, Omura S, Stec DE, Rodella L, Botros FT, Goodman Al, Drummond G, Abraham NG: Genetic suppression of HO-1 exacerbates renal damage: reversed by an increase in the antiapoptotic signaling pathway. Am J Physiol Renal Physiol 2007, 292:F148-F157.

41. Turkseven S, Drummond G, Rezzani R, Rodella L, Quan S, Ikehara S, Abraham NG: Impact of silencing HO-2 on EC-SOD and the mitochondrial signaling pathway. J Cell Biochem 2007, 100:815-823.

42. Tang LM, Wang YP, Wang K, Pu LY, Zhang F, Li XC, Kong LB, Sun BC, Li GQ Wang $\mathrm{XH}$ : Exogenous biliverdin ameliorates ischemia-reperfusion injury in small-for-size rat liver grafts. Transplant Proc 2007, 39:1338-1344.

43. Orino K, Lehman L, Tsuji Y, Ayaki H, Torti SV, Torti FM: Ferritin and the response to oxidative stress. Biochem J 2001, 357:241-247.

44. Otterbein LE, Bach FH, Alam J, Soares M, Tao Lu H, Wysk M, Davis RJ, Flavell RA, Choi AM: Carbon monoxide has anti-inflammatory effects involving the mitogen-activated protein kinase pathway. Nat Med 2000, 6:422-428

45. Brouard S, Otterbein LE, Anrather J, Tobiasch E, Bach FH, Choi AM, Soares MP: Carbon monoxide generated by heme oxygenase 1 suppresses endothelial cell apoptosis. J Exp Med 2000, 192:1015-1026.

46. Brouard S, Berberat PO, Tobiasch E, Seldon MP, Bach FH, Soares MP: Heme oxygenase-1-derived carbon monoxide requires the activation of transcription factor NF-kappa B to protect endothelial cells from tumor necrosis factor-alpha-mediated apoptosis. J Biol Chem 2002 277:17950-17961.

47. Zhang X, Shan P, Otterbein LE, Zhang SS, Otterbein LE, Fu XY, Lee PJ: Carbon monoxide inhibition of apoptosis during ischemia-reperfusion lung injury is dependent on the p38 mitogen- activated protein kinase pathway and involves caspase-3. J Biol Chem 2003, 278:1248-1258.

doi:10.1186/1476-511X-9-124

Cite this article as: Nan et al: Heme oxygenase- 1 prevents non-

alcoholic steatohepatitis through suppressing hepatocyte apoptosis in mice. Lipids in Health and Disease 2010 9:124.

\section{Submit your next manuscript to BioMed Central and take full advantage of:}

- Convenient online submission

- Thorough peer review

- No space constraints or color figure charges

- Immediate publication on acceptance

- Inclusion in PubMed, CAS, Scopus and Google Scholar

- Research which is freely available for redistribution

Submit your manuscript at www.biomedcentral.com/submit 